\title{
Exogenous hydrogen sulfide protects against high glucose-induced inflammation and cytotoxicity in $\mathrm{H9c} 2$ cardiac cells
}

\author{
ZENA HUANG ${ }^{*}$, XIAOBIAN DONG ${ }^{*}$, XIAODONG ZHUANG, XUN HU, LICHUN WANG and XINXUE LIAO \\ Department of Cardiology, The First Affiliated Hospital of Sun Yat-sen University, Guangzhou, Guangdong 510080, P.R. China
}

Received September 19, 2015; Accepted September 2, 2016

DOI: $10.3892 / \mathrm{mmr} .2016 .5846$

\begin{abstract}
Hyperglycemia serves an important role in the pathogenesis of diabetic cardiomyopathy. The aim of the present study was to investigate whether exogenous hydrogen sulfide $\left(\mathrm{H}_{2} \mathrm{~S}\right)$ protects against high glucose-induced inflammation and cytotoxicity in cardiac cells by inhibiting the p38 mitogen-activated protein kinase (MAPK)/nuclear factor- $\kappa \mathrm{B}$ $(\mathrm{NF}-\kappa \mathrm{B})$, cyclooxygenase-2 (COX-2) and inducible nitric oxide synthase (iNOS) signaling pathways. Rat H9c2 myocardium cells were exposed to $33 \mathrm{mM}$ glucose (high glucose, $\mathrm{HG}$ ) for $24 \mathrm{~h}$ to stimulate $\mathrm{HG}$-induced cytotoxicity. One group of cells was pretreated with $\mathrm{NaHS}$ (a donor of $\mathrm{H}_{2} \mathrm{~S}$ ) prior to $\mathrm{HG}$ exposure, and cell viability was determined using the Cell Counting Kit- 8 assay. The protein expression levels of p38MAPK, the phosphorylated p65 subunit of NF- $\mathrm{B}$, iNOS, COX-2 and caspase-3 were analyzed by western blotting, and the protein expression levels of interleukin (IL)-1 $\beta$ and IL-6 were detected by enzyme-linked immunosorbent assay (ELISA). Pretreatment of H9c2 cells with NaHS for $30 \mathrm{~min}$ prior to exposure to HG significantly ameliorated the expression of p38MAPK and NF- $\kappa$ B. In addition, pretreatment with NaHS markedly attenuated p38MAPK/NF- $\kappa$ B-mediated cytotoxicity and inflammation, as evidenced by the significant increase in cell viability and decrease in iNOS, COX-2, IL-1 $\beta$ and IL-6 expression levels. Furthermore, treatment of cells with NaHS significantly decreased the expression of caspase-3, which suggested that NaHS attenuated HG-induced apoptosis. In conclusion, the results of the present study provided evidence to suggest that exogenous $\mathrm{H}_{2} \mathrm{~S}$ protects against $\mathrm{HG}$-induced cytotoxicity and inflammation in $\mathrm{H} 9 \mathrm{c} 2$ cardiac cells. $\mathrm{H}_{2} \mathrm{~S}$
\end{abstract}

Correspondence to: Professor Xinxue Liao or Professor Lichun Wang, Department of Cardiology, The First Affiliated Hospital of Sun Yat-sen University, 58 Zhongshan Road II, Guangzhou, Guangdong 510080, P.R. China

E-mail: liaoxinx@mail.sysu.edu.cn

E-mail: wanglich@mail.sysu.edu.cn

${ }^{*}$ Contributed equally

Key words: hyperglycemia, hydrogen sulfide, cardiac cell, apoptosis, inflammation may exert these cytoprotective effects via inhibition of the p38MAPK/NF- $\kappa$ B , COX-2 and iNOS signaling pathways.

\section{Introduction}

Over the last 30 years, the number of patients with diabetes has increased $>2$-fold, which renders it a major threat to human health (1). Among the complications associated with diabetes, diabetic cardiomyopathy (DCM) is characterized by structural and functional alterations in the myocardium, and is one of the leading causes of morbidity and mortality in patients with diabetes worldwide $(2,3)$. Hyperglycemia-induced cardiac inflammation and cytotoxicity are the major pathological causes of DCM. In the hearts of leptin receptor-deficient $\mathrm{db} / \mathrm{db}$ and streptozotocin (STZ)-induced diabetic mice, hyperglycemia was demonstrated to induce cytotoxicity of cardiac myocytes (4).

Recently, an increasing number of studies have focused on elucidating the signal transduction pathways associated with high glucose (HG)-induced inflammation and cytotoxicity in cardiac tissues $(2,5,6)$. Hyperglycemia may activate the p38 mitogen-activated protein kinase (MAPK) pathway (7), which serves a critical role in the activation of nuclear factor- $\kappa \mathrm{B}$ $(\mathrm{NF}-\kappa \mathrm{B}) . \mathrm{NF}-\kappa \mathrm{B}$ is an essential transcription factor that regulates the expression of proinflammatory genes, including inducible nitric oxide synthase (iNOS), cyclooxygenase-2 (COX-2), interleukin (IL)-1 $\beta$ and IL-6 (8). In addition, activation of NF- $\mathrm{B}$ may upregulate the transcription of specific genes involved in the inflammatory response (9). iNOS mediates the nitrosylation of caspase-3, which may lead to cardiomyocyte cell death (10). COX-2 has been demonstrated to induce cardiomyocyte apoptosis in several mouse models of cardiomyopathy $(11,12)$. Soetikno et al $(13)$ demonstrated that curcumin prevents DCM in STZ-induced diabetic rats by inhibiting the activation of the $\mathrm{p} 38 \mathrm{MAPK} / \mathrm{NF}-\kappa \mathrm{B}$ signaling pathway. Therefore, molecules that function to inhibit p38MAPK/NF- $\mathrm{B}, \mathrm{COX}-2$ and iNOS activation may protect against $\mathrm{HG}$-induced cardiomyocyte injury.

Hydrogen sulfide $\left(\mathrm{H}_{2} \mathrm{~S}\right)$ is synthesized from cysteine by cystathionine gamma lyase, as well as additional naturally occurring enzymes. Along with nitric oxide and carbon monoxide, $\mathrm{H}_{2} \mathrm{~S}$ forms part of a group of biologically active gases termed gasotransmitters or gasomediators (14-16). An increasing number of previous studies have demonstrated that $\mathrm{H}_{2} \mathrm{~S}$ is an important cardioprotective agent $(17,18)$. One such 
study indicated that exogenous $\mathrm{H}_{2} \mathrm{~S}$ exhibits cardioprotective effects by inhibiting oxidative stress and enhancing heat shock protein 90 expression levels (17). Guo et al (19) reported that $\mathrm{H}_{2} \mathrm{~S}$ may protect against doxorubicin-induced inflammation and cytotoxicity in cardiomyocytes by inhibiting the $\mathrm{p} 38 \mathrm{MAPK} / \mathrm{NF}-\kappa \mathrm{B}$ signaling pathway. In diabetic rats and in vitro models, $\mathrm{H}_{2} \mathrm{~S}$ was reported to protect cardiomyocytes from inflammation and cell death (20-22). However, the mechanisms underlying these protective effects of $\mathrm{H}_{2} \mathrm{~S}$ in diabetic cardiomyocytes remain unclear. Therefore, the aim of the present study was to investigate the cardioprotective effects of $\mathrm{H}_{2} \mathrm{~S}$ against HG-induced injury in cardiomyocytes, and to determine whether this may involve the p38MAPK/NF- $\kappa$ B, COX-2 and iNOS signaling pathways.

\section{Materials and methods}

Reagents. The sodium $\mathrm{H}_{2} \mathrm{~S}$ donor (NaHS), the selective inhibitor of p38MAPK (SB203580), the selective inhibitor of NF- $\kappa \mathrm{B}$ (pyrrolidine dithiocarbamate, PDTC), and glucose were purchased from Sigma-Aldrich (Merck Millipore, Darmstadt, Germany). The Cell Counting Kit-8 (CCK-8) assay was purchased from Dojindo Molecular Technologies, Inc. (Kumamoto, Japan). Primary antibodies specific to the phosphorylated (p)-p65 as a measure of NF- $\mathrm{kB}$ protein expression levels, COX-2, caspase-3, and p38 were purchased from Cell Signaling Technology, Inc. (Danvers, MA, USA; cat. nos. 3033, 12282, 9665 and 4511, respectively). The horseradish peroxidase-conjugated goat anti-rabbit IgG secondary antibody (cat. no. KC-RB-035), and the enzyme linked immunosorbent assay (ELISA) kits for assessing IL-1 $\beta$ and IL-6 expression levels were purchased from Zhejiang Kangchen Biotech Co., Inc. (Hangzhou, China). The primary antibody against iNOS (cat no. sc650) was purchased from Santa Cruz Biotechnology, Inc. (Dallas, TX, USA). The primary glyceraldehyde 3-phosphate dehydrogenase (GAPDH) antibody (cat. no. HJTW0125) was purchased from Guangzhou Jetway Biotech Co., Ltd. (Guangzhou, China). The interleukin-1 receptor antagonist (IL-1Ra) was purchased from Prospec-Tany TechnoGene, Ltd. (East Brunswick, NJ, USA). The bicinchoninic acid (BCA) protein assay kit was purchased from Thermo Fisher Scientific, Inc. (Waltham, MA, USA). The radioimmunoprecipitation assay (RIPA) buffer was purchased from Beyotime Institute of Biotechnology (Shanghai, China). Low-glucose Dulbecco's modified Eagle's medium-Ham's F12 (DMEM-F12), phosphate-buffered saline (PBS) and fetal bovine serum (FBS) were purchased from Gibco; Thermo Fisher Scientific, Inc. $\mathrm{H} 9 \mathrm{c} 2$ cells were obtained from the Sun Yat-sen University Experimental Animal Center (Guangzhou, China).

Cell culture and treatments. $\mathrm{H} 9 \mathrm{c} 2$ cardiac cells were cultured in DMEM-F12 medium supplemented with $10 \% \mathrm{FBS}$ at $37^{\circ} \mathrm{C}$ and $5 \% \mathrm{CO}_{2}$. In order to investigate the cytotoxic effects of HG, H9c2 cells were treated with 11, 22, 33 or $44 \mathrm{mM}$ glucose for $24 \mathrm{~h}$. To investigate the cardioprotective effects of $\mathrm{H}_{2} \mathrm{~S}$ on HG-induced injury, the cells were pretreated with $400 \mu \mathrm{M}$ NaHS for 30 min prior to HG treatment. To further determine whether the anti-inflammatory effects of $\mathrm{H}_{2} \mathrm{~S}$ were associated with inhibition of p38MAPK/NF- $\mathrm{BB}$ pathway, H9c2 cells were pretreated with $3 \mu \mathrm{M} \mathrm{SB} 203580$ (a selective inhibitor of p38MAPK) for 60 min or $100 \mu \mathrm{M}$ PDTC (a selective inhibitor of NF- $\mathrm{kB}$ ) for $30 \mathrm{~min}$ prior to HG treatment, or were co-treated with HG plus $20 \mathrm{ng} / \mathrm{ml} \mathrm{IL-1Ra} \mathrm{(a} \mathrm{selective} \mathrm{antagonist} \mathrm{of} \mathrm{the}$ IL-1 $\beta$ receptor) for $24 \mathrm{~h}$.

Cell viability assay. H9c2 cells were cultured in 96-well plates $\left(1 \times 10^{4}\right.$ cells/well) and were divided into the following groups: $\mathrm{HG}, \mathrm{HG}+\mathrm{NaHS}, \mathrm{HG}+\mathrm{SB} 203580, \mathrm{HG}+\mathrm{PDTC}$, HG+IL-Ra, NaHS, SB203580, PDTC or IL-1Ra) before $10 \mu \mathrm{l}$ CCK-8 solution was added to each well at a dilution of 1:10, and the cells were incubated for $2 \mathrm{~h}$. The absorbance was measured at $450 \mathrm{~nm}$ using a Multiskan MK3 microplate reader (Thermo Fisher Scientific, Inc.). The mean optical density (OD) of five wells for each treatment group was used to calculate the percentage cell viability relative to untreated control cells, according to the following formula: Cell viability $(\%)=\left(\mathrm{OD}_{\text {treatment }} / \mathrm{OD}_{\text {control }}\right) \times 100$. The experiments were performed in triplicate.

Detection of $I L-1 \beta$ and $I L-6$ production in the cell culture media using ELISA. H9c2 cells were plated in $60 \mathrm{~mm}$ dishes at a density of $1 \times 10^{6}$ cells/well. Cells were divided into the following treatment groups: $\mathrm{HG}, \mathrm{HG}+\mathrm{NaHS}, \mathrm{HG}+\mathrm{SB} 203580$, HG+PDTC, HG+IL-Ra, NaHS, SB203580, PDTC or IL-1Ra. The level of IL-1 $\beta$ and IL- 6 in the culture media was determined using ELISA, according to the manufacturer's instructions. The absorbance was read at $450 \mathrm{~nm}$, and experiments were performed $>5$ times.

Extraction of cytoplasmic and nuclear proteins. H9c2 cells were plated in $60 \mathrm{~mm}$ dishes at a density of $1 \times 10^{6}$ cells/well and divided into the following treatment groups: HG, HG+NaHS, HG+SB203580, HG+PDTC, HG+IL-Ra, NaHS, SB203580, PDTC or IL-1Ra. Cytoplasmic and nuclear proteins from $\mathrm{H} 9 \mathrm{c} 2$ cells were isolated using the NE-PER Nuclear and Cytoplasmic Extraction Reagent kit, according to the manufacturer's instructions (Thermo Fisher Scientific, Inc.). Briefly, after washing three times with cold PBS, the cells were treated with cytoplasmic protein extraction buffer to isolate cytoplasmic protein fraction proteins. The nuclear proteins were subsequently extracted by adding the nuclear protein extraction buffer. Cytoplasmic and nuclear protein extracts were subject to western blot analysis.

Western blot analysis. H9c2 cells were seeded in $60-\mathrm{mm}$ dishes at a density of $1 \times 10^{6}$ cells/well and divided into the following treatment groups: $\mathrm{HG}, \mathrm{HG}+\mathrm{NaHS}, \mathrm{HG}+\mathrm{SB} 203580$, HG+PDTC, HG+IL-Ra, NaHS, SB203580, PDTC or IL-1Ra, Cells were washed in PBS and lysed in RIPA buffer for $30 \mathrm{~min}$, and the homogenate was centrifuged at 21,380 $\mathrm{x} g$ for $10 \mathrm{~min}$ at $4^{\circ} \mathrm{C}$. The total protein concentration of the sample supernatant was determined using a BCA protein assay kit. Total protein $(30 \mu \mathrm{g})$ was separated by $12 \%$ sodium dodecyl sulfate-polyacrylamide gel electrophoresis. The proteins were then transferred onto a polyvinylidene difluoride membrane and the membrane was blocked with 5\% non-fat milk diluted in Tris-buffered saline- $0.1 \%$ Tween 20 (TBS-T) for $1 \mathrm{~h}$ at room temperature. The membranes were subsequently incubated with primary antibodies specific to phosphorylated 
(p)-p65 (dilution, 1:500), iNOS (dilution, 1:1,000), COX-2 (dilution, 1:1,000), caspase-3 (dilution, 1:1,000), p-p38 (dilution, 1:1,000) or GAPDH (dilution, 1:10,000) with gentle agitation at $4^{\circ} \mathrm{C}$ overnight. The following day, the membranes were incubated with secondary antibodies (dilution, 1:5,000) for $1.5 \mathrm{~h}$ at room temperature. Following three washes with TBS-T, the membranes were developed using enhanced chemiluminescence and exposed to X-ray films. To quantify protein expression levels, the X-ray films were visualized and analyzed using ImageJ software (version, 1.41; National Institutes of Health, Bethesda, MA, USA).

Statistical analysis. The data are presented as the mean \pm standard error. Differences among treatment groups were analyzed using one-way analysis of variance with the least significant difference test. Statistical analyses were performed using the SPSS software program (version, 13.0; SPSS, Inc., Chicago, IL, USA). $\mathrm{P}<0.05$ was considered to indicate a statistically significant difference.

\section{Results}

$H G$ decreased cell viability in a concentration-dependent and time-dependent manner. In order to investigate the cytotoxic effects of HG, H9c2 cells were treated with 11,22, 33 or $44 \mathrm{mM}$ glucose for $24 \mathrm{~h}$ As shown in Fig. 1, a significant reduction in cell viability was observed following treatment with $33 \mathrm{mM}$ HG when compared with untreated controls $(58.10 \pm 2.24 \%$ reduction; $\mathrm{P}<0.01)$. Based on these results, together with those of a previous study (21), treatment of cells with $33 \mathrm{mM} \mathrm{HG}$ for $24 \mathrm{~h}$ was selected to model the effects of hyperglycemia on cardiac cells in vitro.

Exogenous $\mathrm{H}_{2} \mathrm{~S}$ attenuates $\mathrm{HG}$-induced cytotoxicity in $\mathrm{H} 9 \mathrm{c} 2$ cells. As shown in Fig. 2A, exposure of $\mathrm{H} 9 \mathrm{c} 2$ cells to $\mathrm{HG}$ for $24 \mathrm{~h}$ induced cytotoxicity, as evidenced by the significant decrease in cell viability $(\mathrm{P}<0.01)$. However, this effect was significantly diminished when the cells were pretreated with $400 \mu \mathrm{M}$ NaHS for 30 min prior to $\mathrm{HG}$ treatment $(\mathrm{P}<0.01)$, which suggests that $\mathrm{H}_{2} \mathrm{~S}$ may attenuate $\mathrm{HG}$-induced cytotoxicity. Similarly, pretreatment of cells with SB203580 or PDTC prior to HG treatment, significantly attenuated the cytotoxic effects of HG treatment (SB203580 and PDTC, $\mathrm{P}<0.01$; Fig. 2A). These results demonstrate that the p38MAPK/NF- $\kappa \mathrm{B}$ signaling pathway may be involved in HG-induced cytotoxicity. Notably, treatment of $\mathrm{H} 9 \mathrm{c} 2$ cells with NaHS alone did not have a significant effect on cell viability (Fig. 2A).

Exogenous $\mathrm{H}_{2} \mathrm{~S}$ inhibits the p38MAPK/NF- $\mathrm{B}$ signaling pathway in $H G$-treated $H 9 c 2$ cells. The next aim of the present study was to investigate the effect of $\mathrm{H}_{2} \mathrm{~S}$ on the p38MAPK/NF- $\mathrm{B}$ signaling pathway. As shown in Fig. $2 \mathrm{~B}$, exposure of $\mathrm{H} 9 \mathrm{c} 2$ cells to $\mathrm{HG}$ for $24 \mathrm{~h}$ significantly enhanced the protein expression levels of p-p38MAPK when compared with untreated controls $(\mathrm{P}<0.01)$. In contrast, pretreatment of cells with $400 \mu \mathrm{M}$ NaHS for 30 min prior to HG treatment was associated with a significant reduction in p-p38 expression when compared with HG-treated cells ( $\mathrm{P}<0.01$; Fig. 2B).

Exposure of $\mathrm{H} 9 \mathrm{c} 2$ cells to $\mathrm{HG}$ for $24 \mathrm{~h}$ significantly increased the expression of $\mathrm{NF}-\kappa \mathrm{B}(\mathrm{P}<0.01$; Fig. $2 \mathrm{C})$. However,

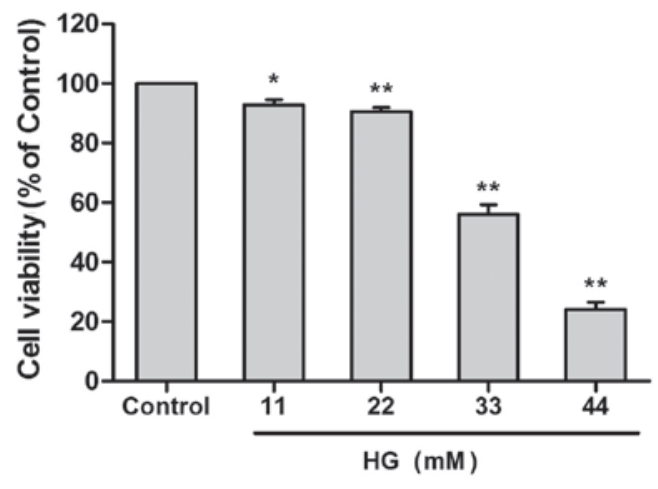

Figure 1. HG decreases cell viability in a concentration-dependent manner. The percentage viability of rat $\mathrm{H} 9 \mathrm{c} 2$ myocardium cells following treatment with different concentrations of glucose as determined using a Cell Counting Kit- 8 assay. The data are presented as the mean \pm standard error $(n=6$; ${ }^{*} \mathrm{P}<0.05$ and $^{* *} \mathrm{P}<0.01$ vs. the untreated control group). HG, high glucose.

pretreatment of cells with $400 \mu \mathrm{M}$ NaHS for 30 min or $3 \mu \mathrm{M}$ SB203580 for 60 min prior to $\mathrm{HG}$ treatment was associated with a significant reduction in p-p65 expression levels (NaHS, $\mathrm{P}<0.01$; SB203580, P<0.01; Fig. 2C). These findings suggest that NaHS may inhibit the expression of NF- $\kappa \mathrm{B}$ and the $\mathrm{p} 38 \mathrm{MAPK} / \mathrm{NF}-\kappa \mathrm{B}$ signaling pathway following exposure to $\mathrm{HG}$.

Exogenous $\mathrm{H}_{2} \mathrm{~S}$ suppresses the $\mathrm{HG}$-induced production of proinflammatory cytokines by inhibiting the p38MAPK/NF- $\mathrm{BB}$ pathway in $H 9$ c 2 cells. Following exposure to $\mathrm{HG}$ for $24 \mathrm{~h}$, the production of COX-2 ( $\mathrm{P}<0.01$; Fig. 3A), iNOS ( $\mathrm{P}<0.01$; Fig. 3B), IL-1 $\beta(\mathrm{P}<0.01$; Fig. 3C) and IL-6 $(\mathrm{P}<0.01$; Fig. 3D) were significantly increased when compared with the untreated control group. However, pretreatment of cells with $400 \mu \mathrm{M}$ NaHS for 30 min prior to $\mathrm{HG}$ exposure, significantly ameliorated the HG-induced increase in COX-2, iNOS, IL-1 $\beta$ and IL- 6 expression levels (COX-2, iNOS, IL-1 $\beta$ and IL-6, P<0.01; Fig. 3A-D). These results suggest that $\mathrm{H}_{2} \mathrm{~S}$ may suppress the production of proinflammatory cytokines in HG-treated H9c2 cells.

Pretreatment of $\mathrm{H} 9 \mathrm{c} 2$ cells with $100 \mu \mathrm{M}$ PDTC for $30 \mathrm{~min}$ prior to $\mathrm{HG}$ exposure attenuated the $\mathrm{HG}$-induced production of COX-2, iNOS, IL-1 $\beta$ and IL-6 (COX-2, iNOS, IL-1 $\beta$ and IL-6, P<0.01; Fig. 3A-D). In addition, H9c2 cells pretreated with $3 \mu \mathrm{M}$ SB203580 for $60 \mathrm{~min}$ prior to HG exposure demonstrated a significant reduction in IL-1 $\beta$ and IL- 6 expression (IL-1 $\beta$ and IL-6, P<0.01; Fig. 3C and D) when compared with HG-treated controls. This suggests that $\mathrm{H}_{2} \mathrm{~S}$ may suppress the HG-induced production of COX-2, iNOS, IL-1 $\beta$ and IL- 6 by inhibiting the $\mathrm{p} 38 \mathrm{MAPK} / \mathrm{NF}-\kappa \mathrm{B}$ signaling pathway in $\mathrm{H} 9 \mathrm{c} 2$ cells.

Exogenous $\mathrm{H}_{2} \mathrm{~S}$ exhibits anti-inflammatory effects by ameliorating the $H G$-induced increase in caspase-3 expression. The results presented so far suggest that exogenous $\mathrm{H}_{2} \mathrm{~S}$ may protect against HG-induced cytotoxicity (Fig. 2A) and reduce the production of proinflammatory cytokines (Fig. 3) in H9c2 cells. Therefore, the final aim of the present study was to investigate whether the anti-inflammatory effects of $\mathrm{H}_{2} \mathrm{~S}$ may attenuate $\mathrm{HG}$-induced apoptosis. Following exposure of $\mathrm{H} 9 \mathrm{c} 2$ cells to HG for $24 \mathrm{~h}$, the expression levels of caspase-3, which is an important inducer of apoptosis (23), were significantly 
increased (Fig. 4). However, pretreatment of cells with $400 \mu \mathrm{M}$ NaHS prior to HG exposure was associated with a significant reduction in caspase-3 expression levels when compared with cells treated with $\mathrm{HG}$ alone $(\mathrm{P}<0.01)$. Similarly, treatment of cells with HG plus $20 \mathrm{ng} / \mathrm{ml}$ IL-1Ra for $24 \mathrm{~h}$ significantly attenuated the production of caspase- 3 when compared with cells exposed to $\mathrm{HG}$ alone $(\mathrm{P}<0.01$; Fig. 4). This suggests that the IL-1 receptor may be involved in mediating the HG-induced increase in caspase-3 expression. These results indicate that exogenous $\mathrm{H}_{2} \mathrm{~S}$ may exhibit anti-inflammatory effects by ameliorating the HG-induced increase in caspase-3 expression, which protects against HG-induced apoptosis.

\section{Discussion}

The results of the present study suggest that exogenous $\mathrm{H}_{2} \mathrm{~S}$ protects cardiac cells against HG-induced inflammation and cytotoxicity, and inhibition of the p38MAPK/NF- $\kappa B$, COX-2 and iNOS signaling pathways may be involved in mediating these cardioprotective effects of $\mathrm{H}_{2} \mathrm{~S}$ in cardiac cells in vitro. In addition, $\mathrm{H}_{2} \mathrm{~S}$ exhibited anti-inflammatory effects by significantly attenuating the HG-induced increase in caspase-3 expression.

Several factors have been implicated in the development of DCM, including metabolic disturbances, myocardial fibrosis, small vessel disease, autonomic dysfunction and insulin resistance (2). Metabolic disturbances, particularly hyperglycemia, initiate the development of DCM (24). Consistent with previous studies $(20,25)$, exposure to $33 \mathrm{mM}$ glucose for $24 \mathrm{~h}$ in the present study, was associated with cytotoxicity and the induction of inflammatory responses in $\mathrm{H} 9 \mathrm{c} 2$ cells, as evidenced by a decrease in cell viability, increased expression of the apoptosis inducing factor-caspase 3 , and an increase in the expression of multiple pro-inflammatory cytokines, including COX-2, iNOS, IL-1 $\beta$ and IL-6. In addition, HG-treated cardiac cells demonstrated an increase in p38MAPK and p-p65 expression, which suggests that the p38MAPK/NF- $\kappa$ B signaling pathway may have been involved in mediating the pro-apoptotic and cytotoxic effects of $\mathrm{HG}$ in H9c2 cells.

The physiological importance of $\mathrm{H}_{2} \mathrm{~S}$ was recognized in the last 15 years. Previous studies have demonstrated that $\mathrm{H}_{2} \mathrm{~S}$ influences a wide range of physiological and pathological processes, including blood vessel dilation (26-28), arterial contraction $(27,29,30)$, neurotransmission (31), the regulation of inflammation $(32,33)$ and cardioprotection $(34,35)$. In patients with diabetes (36) and in rats with STZ-induced diabetes $(36,37)$, the levels of $\mathrm{H}_{2} \mathrm{~S}$ in the circulation were significantly reduced. Therefore, a significant amount of attention has focused on investigating whether exogenous $\mathrm{H}_{2} \mathrm{~S}$ supplementation may protect cardiac cells from diabetes-induced cardiac injury. Several studies have revealed that exogenous $\mathrm{H}_{2} \mathrm{~S}$ protects against $\mathrm{HG}$-induced cytotoxicity and inflammation in cardiac cells $(20,21)$. A previous in vivo study demonstrated that intraperitoneal or oral administration of $\mathrm{H}_{2} \mathrm{~S}$ reduced myocardial hypertrophy, as well as the degree of fibrosis (18). Consistent with previous studies, the results of the present study demonstrate that exogenous $\mathrm{H}_{2} \mathrm{~S}$ may protect against cytotoxicity and inflammation in HG-treated $\mathrm{H} 9 \mathrm{c} 2$ cells.

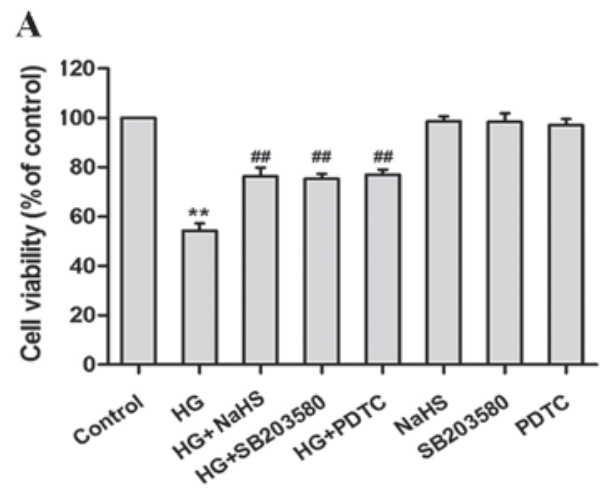

B
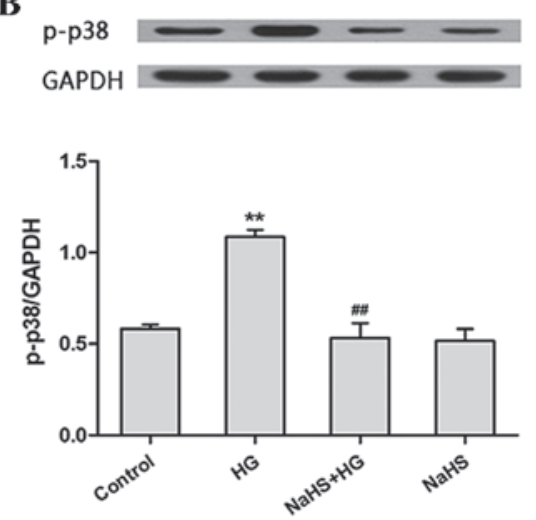

C
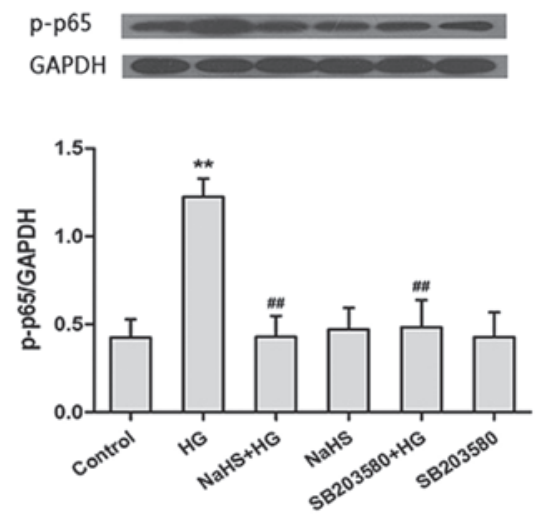

Figure 2. $\mathrm{H}_{2} \mathrm{~S}$ attenuates $\mathrm{HG}$-induced cytotoxicity by inhibiting the p38MAPK/NF- $\kappa \mathrm{B}$ signaling pathway in H9c2 cells. (A) The viability of rat $\mathrm{H} 9 \mathrm{c} 2$ myocardium cells following pretreatment with NaHS, SB203580 (a selective inhibitor of p38MAPK) or PDTC (a selective inhibitor of NF- $\mathrm{kB}$ ) prior to HG treatment was significantly increased compared with the cells treated with $\mathrm{HG}$ alone, as determined using the Cell Counting Kit- 8 assay $(n=6)$. (B) Pretreatment with NaHS significantly diminished the HG-induced increase in p-p38 protein expression levels in $\mathrm{H} 9 \mathrm{c} 2$ cells, as determined by western blotting $(n=3)$. (C) Pretreatment with NaHS or SB203580 significantly reduced the $\mathrm{HG}$-induced increase in p-p65 protein expression in $\mathrm{H} 9 \mathrm{c} 2$ cells, as determined by western blotting $(n=3)$. Protein expression levels are presented relative to GAPDH. The data are presented as the mean \pm standard error. ( $^{* *} \mathrm{P}<0.01$ vs. the control group; ${ }^{\# \#} \mathrm{P}<0.01$ vs. the HG treatment group). MAPK, mitogen-activated protein kinase; NF- $\kappa \mathrm{B}$, nuclear factor- $\kappa \mathrm{B}$; PDTC, pyrrolidine dithiocarbamate; HG, high glucose; $\mathrm{p}-$, phosphorylated-; GAPDH, glyceraldehyde 3-phosphate dehydrogenase.

The present study investigated the mechanisms underlying the cardioprotective effects of $\mathrm{H}_{2} \mathrm{~S}$ against $\mathrm{HG}$-induced cytotoxicity in $\mathrm{H} 9 \mathrm{c} 2$ cells. Exogenous $\mathrm{H}_{2} \mathrm{~S}$ inhibited the HG-induced activation of the p38MAPK/NF- $\mathrm{kB}$ signaling pathway, and 
A
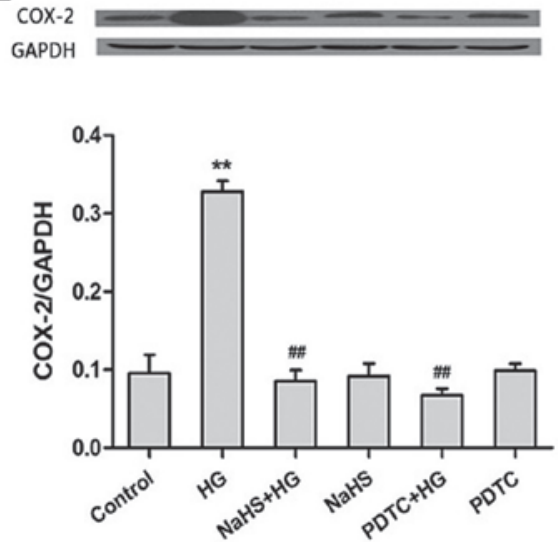

C

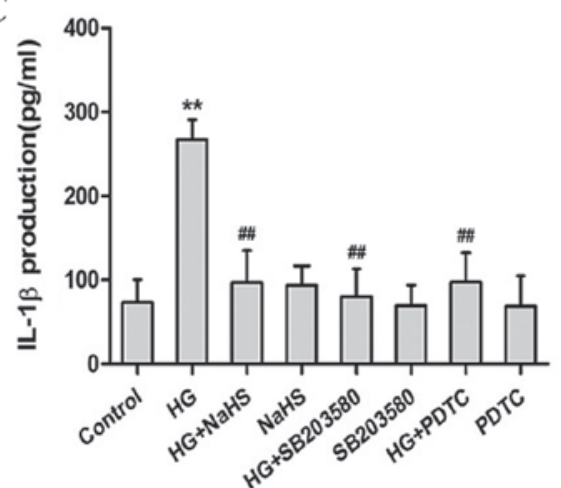

B

iNOS GAPDH

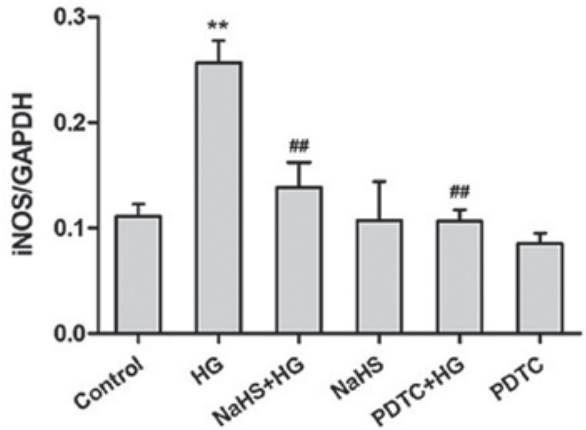

D

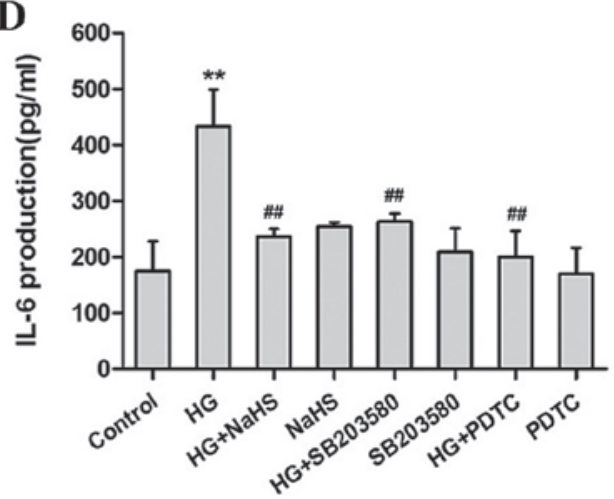

Figure 3. $\mathrm{H}_{2} \mathrm{~S}$ downregulates the HG-induced increase in proinflammatory cytokine expression via the p38MAPK/NF-kB signaling pathway. Pretreatment of rat $\mathrm{H} 9 \mathrm{c} 2$ cells with NaHS or PDTC (a selective inhibitor of NF-kB) prior to HG exposure significantly reduced the HG-induced increase in (A) COX-2, (B) iNOS, (C) IL-1 $\beta$ and (D) IL-6 protein expression levels, as determined by (A and B) western blotting and (C and D) enzyme-linked immunosorbent assay analyses. Protein expression levels are presented relative to GAPDH. Pretreatment of cells with SB203580 (a selective inhibitor of p38MAPK) prior to HG exposure significantly attenuated the HG-induced increase in (C) IL-1 $\beta$ and (D) IL-6 expression levels. The data are presented as the mean \pm standard error ( $\mathrm{n}=3 ;{ }^{* *} \mathrm{P}<0.01$ vs. the untreated control group; ${ }^{\# \#} \mathrm{P}<0.01$ vs. the HG treatment group). HG, high glucose; MAPK, mitogen-activated protein kinase; NF-kB, nuclear factor-kB; PDTC, pyrrolidine dithiocarbamate; COX-2, cyclooxygenase-2; iNOS, inducible nitric oxide synthase; IL, interleukin; GAPDH, glyceraldehyde 3-phosphate dehydrogenase.

Cleaved caspase-3

\section{GAPDH}

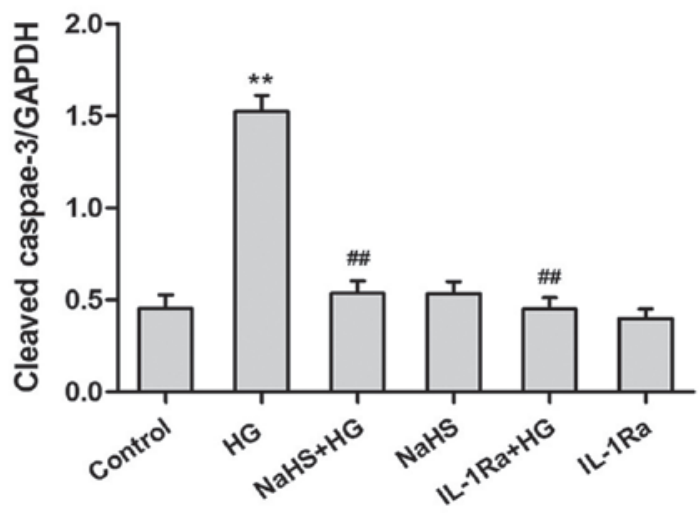

Figure $4 . \mathrm{H}_{2} \mathrm{~S}$ exhibits anti-inflammatory effects by ameliorating the $\mathrm{HG}$-induced increase in caspase-3 expression. Pretreatment of rat $\mathrm{H} 9 \mathrm{c} 2$ cells with NaHS or IL-1Ra prior to HG exposure significantly attenuated the HG-induced increase in cleaved caspase- 3 expression, as determined by western blotting. Protein expression levels are presented relative to GAPDH. The data are presented as the mean \pm standard error $\left(\mathrm{n}=3 ;{ }^{* *} \mathrm{P}<0.01 \mathrm{vs}\right.$. the control group; ${ }^{\# \#} \mathrm{P}<0.01$ vs. the $\mathrm{HG}$ treatment group). $\mathrm{HG}$, high-glucose; IL-1Ra, interleukin-1 receptor antagonist; GAPDH, glyceraldehyde 3-phosphate dehydrogenase. significantly attenuated the HG-induced cytotoxicity of HG-treated $\mathrm{H} 9 \mathrm{c} 2$ cells. Consistent with these observations, $\mathrm{H}_{2} \mathrm{~S}$ has been demonstrated to inhibit p38MAPK activity in various cell types, including rat aortic vascular smooth muscle cells (38), microglia (32) and neuroblastoma cells (39). In addition, $\mathrm{H}_{2} \mathrm{~S}$ has been demonstrated to inhibit NF- $\mathrm{KB}$ activation and nuclear translocation in macrophages (40), kidney cells (41), pancreatic acinar cells (42) and heart cells (43). It is possible that activation of the p38MAPK signaling pathway may be a common mechanism involved in the pathogenesis of chronic complications associated with diabetes, as the elevation of p-p38MAPK in mouse diabetic cardiomyocytes activates the production of several cytokines (44). NF- $\mathrm{\kappa B}$ is a key factor involved in inflammation, which regulates the transcription of $>100$ genes associated with immune and inflammatory responses (16). The functional consequence of reduced NF-kB activation in cells is a downregulation in the number of activated proinflammatory genes and cytokines, including COX-2, iNOS, IL-1 $\beta$ and IL-6. Zheng et al (45) observed that downregulation of the NF- $\mathrm{KB}$ pathway reduced the downstream expression of proinflammatory genes, including IL-1 $\beta$, IL- 6 and tumor necrosis factor- $\alpha$, which led to attenuation of inflammation-mediated injury of the vascular wall. These data support the role of $\mathrm{H}_{2} \mathrm{~S}$ as a cardioprotective agent against HG-induced inflammation 
and cytotoxicity through modulating the activity of the p38MAPK/NF- $\mathrm{B}$ signaling pathway in $\mathrm{H} 9 \mathrm{c} 2$ cells.

iNOS is an enzyme and can be induced in all cells and tissues through the action of cytokines (46). Activation of iNOS has been associated with the development of cardiovascular complications in rat models of diabetes. Bardell et al (47) demonstrated that the expression of iNOS in the mesenteric arteries is increased in rat models of diabetes. In the present study, the expression levels of iNOS were significantly elevated in cardiac cells following exposure to $\mathrm{HG}$, which were significantly attenuated by $\mathrm{H}_{2} \mathrm{~S}$ treatment or following inhibition of $\mathrm{NF}-\kappa \mathrm{B}$. A previous study, involving STZ-induced diabetic rats, demonstrated that iNOS mediated the nitrosylation of GAPDH and caspase-3, which led to cardiomyocyte death (5). Therefore, the p38MAPK/NF- $\kappa \mathrm{B}$ and iNOS signaling pathways are likely to be involved in mediating the cardioprotective effects of exogenous $\mathrm{H}_{2} \mathrm{~S}$ against $\mathrm{HG}$-induced inflammation and cytotoxicity in $\mathrm{H} 9 \mathrm{c} 2$ cells.

COX is an enzyme involved in the metabolism of arachidonic acid (AA), and the COX-2 isoform is a key enzyme in the conversion of AA to prostaglandins (48). A previous study demonstrated that overexpression of COX-2 is correlated with induction of inflammatory processes (49). In the present study, the level of COX-2 expression was significantly elevated in cardiac cells following $\mathrm{HG}$ exposure. In addition, exposure of cardiac $\mathrm{H} 9 \mathrm{c} 2$ cells to $\mathrm{H}_{2} \mathrm{~S}$ or a specific inhibitor to $\mathrm{NF}-\kappa \mathrm{B}$, abolished the HG-induced increase in COX-2 expression. In a rat model of heart ischemia/reperfusion injury (50), inhibition of COX-2 was associated with a reduction in cellular apoptosis. Consistent with these observations, the results of the present study suggest that $\mathrm{H}_{2} \mathrm{~S}$ may attenuate apoptosis of $\mathrm{H} 9 \mathrm{c} 2$ cells following $\mathrm{HG}$ exposure by reducing caspase-3 expression levels. Therefore, $\mathrm{H}_{2} \mathrm{~S}$ may protect cardiac cells by inhibiting COX-2 expression potentially through modulating the $\mathrm{p} 38 \mathrm{MAPK} / \mathrm{NF}-\kappa \mathrm{B}$ signaling pathway.

In the present study, pretreatment of $\mathrm{H} 9 \mathrm{c} 2$ cells with an IL-1Ra prior to HG exposure significantly reduced caspase-3 expression. This suggests that inhibition of inflammation may protect against HG-induced apoptosis in $\mathrm{H} 9 \mathrm{c} 2$ cells. Consistent with this observation, inhibition of the inflammatory response significantly reduced doxorubicin-induced cytotoxicity of $\mathrm{H} 9 \mathrm{c} 2$ cells (19). In addition, p38MAPK was demonstrated to promote apoptosis in a number of in vitro models, such as pulmonary microvascular endothelial cells (51) and breast cancer cells (52), while $\mathrm{H}_{2} \mathrm{~S}$ prevented apoptosis by inhibition of p38MAPK (53). Therefore, the p38MAPK/NF- $\kappa$ B pathway-mediated activation of the anti-inflammatory response may be associated with the cardioprotective effects of exogenous $\mathrm{H}_{2} \mathrm{~S}$ treatment against $\mathrm{HG}$-induced cytotoxicity in $\mathrm{H} 9 \mathrm{c} 2$ cells.

In conclusion, the results of the present study demonstrated that exogenous $\mathrm{H}_{2} \mathrm{~S}$ exhibits cardioprotective effects against HG-induced cytotoxicity and inflammation in rat cardiac cells in vitro. $\mathrm{H}_{2} \mathrm{~S}$ exerted cytoprotective effects potentially via the p38MAPK/NF- $\mathrm{BB}$-mediated anti-inflammatory and antiapoptotic signaling pathways. The results provide evidence to suggest that $\mathrm{H}_{2} \mathrm{~S}$ may have a potential therapeutic value in hyperglycemia-induced cardiac lesions, which are predominant in DCM.

\section{Acknowledgements}

The present study was supported by the National Nature Science Foundation of China (grant no. 81270296) and the Social Development Project of Guangdong Province in China (grant no. 2014SC107).

\section{References}

1. Chen L, Magliano DJ and Zimmet PZ: The worldwide epidemiology of type 2 diabetes mellitus-present and future perspectives. Nat Rev Endocrinol 8: 228-236, 2011.

2. Goyal BR and Mehta AA: Diabetic cardiomyopathy: Pathophysiological mechanisms and cardiac dysfuntion. Hum Exp Toxicol 32: 571-590, 2013.

3. Poornima IG, Parikh P and Shannon RP: Diabetic cardiomyopathy: The search for a unifying hypothesis. Circ Res 98: 596-605, 2006.

4. Shen E, Li Y, Li Y, Shan L, Zhu H, Feng Q, Arnold JM and Peng T: Racl is required for cardiomyocyte apoptosis during hyperglycemia. Diabetes 58: 2386-2395, 2009.

5. Puthanveetil P, Zhang D, Wang Y, Wang F, Wan A, Abrahani A and Rodrigues B: Diabetes triggers a PARP1 mediated death pathway in the heart through participation of FoxO1. J Mol Cell Cardiol 53: 677-686, 2012.

6. Evans JL, Goldfine ID, Maddux BA and Grodsky GM: Oxidative stress and stress-activated signaling pathways: A unifying hypothesis of type 2 diabetes. Endocr Rev 23: 599-622, 2002.

7. Igarashi M, Wakasaki H, Takahara N, Ishii H, Jiang ZY, Yamauchi T, Kuboki K, Meier M, Rhodes CJ and King GL: Glucose or diabetes activates p38 mitogen-activated protein kinase via different pathways. J Clin Invest 103: 185-195, 1999.

8. Crowell JA, Steele VE, Sigman CC and Fay JR: Is inducible nitric oxide synthase a target for chemoprevention? Mol Cancer Ther 2: 815-823, 2003.

9. Cho SY, Park SJ, Kwon MJ, Jeong TS, Bok SH, Choi WY, Jeong WI, Ryu SY, Do SH, Lee CS, et al: Quercetin suppresses proinflammatory cytokines production through MAP kinases and NF-kappaB pathway in lipopolysaccharide-stimulated macrophage. Mol Cell Biochem 243: 153-160, 2003.

10. Puthanveetil P, Zhang D, Wang Y, Wang F, Wan A, Abrahani A and Rodrigues B: Diabetes triggers a PARP1 mediated death pathway in the heart through participation of FoxO1. J Mol Cell Cardiol 53: 677-686, 2012.

11. Jenke A, Wilk S, Poller W, Eriksson U, Valaperti A, Rauch BH, Stroux A, Liu P, Schultheiss HP, Scheibenbogen C and Skurk C: Adiponectin protects against Toll-like receptor 4-mediated cardiac inflammation and injury. Cardiovasc Res 99: 422-431, 2013.

12. Streicher JM, Kamei K, Ishikawa TO, Herschman H and Wang Y: Compensatory hypertrophy induced by ventricular cardiomyocyte-specific COX-2 expression in mice. J Mol Cell Cardiol 49: 88-94, 2010

13. Soetikno V, Sari FR, Sukumaran V, Lakshmanan AP, Mito S, Harima M, Thandavarayan RA, Suzuki K, Nagata M, Takagi R and Watanabe K: Curcumin prevents diabetic cardiomyopathy in streptozotocin-induced diabetic rats: Possible involvement of PKC-MAPK signaling pathway. Eur J Pharm Sci 47: 604-614, 2012.

14. Liu YH, Lu M, Hu LF, Wong PT, Webb GD and Bian JS. Hydrogen sulfide in the mammalian cardiovascular system. Antioxid Redox Signal 17: 141-185, 2012.

15. Holwerda KM, Karumanchi SA and Lely AT: Hydrogen sulfide: Role in vascular physiology and pathology. Curr Opin Nephrol Hypertens 24: 170-176, 2015.

16. Li L, Bhatia M and Moore PK: Hydrogen sulphide-A novel mediator of inflammation? Curr Opin Pharmacol 6: 125-129, 2006.

17. Chen SL, Yang CT, Yang ZL, Guo RX, Meng JL, Cui Y, Lan AP, Chen PX and Feng JQ: Hydrogen sulphide protects H9c2 cells against chemical hypoxia-induced injury. Clin Exp Pharmacol Physiol 37: 316-321, 2010.

18. El-Seweidy MM, Sadik NA and Shaker OG: Role of sulfurous mineral water and sodium hydrosulfide as potent inhibitors of fibrosis in the heart of diabetic rats. Arch Biochem Biophys 506: 48-57, 2011 
19. Guo R, Wu K, Chen J, Mo L, Hua X, Zheng D, Chen P, Chen G, $\mathrm{Xu} \mathrm{W}$ and Feng J: Exogenous hydrogen sulfide protects against doxorubicin-induced inflammation and cytotoxicity by inhibiting p38MAPK/NFkB pathway in H9c2 cardiac cells. Cell Physiol Biochem 32: 1668-1680, 2013.

20. Xu W, Wu W, Chen J, Guo R, Lin J, Liao X and Feng J: Exogenous hydrogen sulfide protects H9c2 cardiac cells against high glucose-induced injury by inhibiting the activities of the p38 MAPK and ERK1/2 pathways. Int J Mol Med 32: 917-925, 2013

21. Wei WB, Hu X, Zhuang XD, Liao LZ and Li WD: GYY4137, a novel hydrogen sulfide-releasing molecule, likely protects against high glucose-induced cytotoxicity by activation of the AMPK/mTOR signal pathway in $\mathrm{H} 9 \mathrm{c} 2$ cells. Mol Cell Biochem 389: 249-256, 2014

22. Zhou X and Lu X: Hydrogen sulfide inhibits high-glucose-induced apoptosis in neonatal rat cardiomyocytes. Exp Biol Med (Maywood) 238: 370-374, 2013.

23. Fulda S: Targeting apoptosis for anticancer therapy. Semin Cancer Biol 31: 84-88, 2015

24. Mortuza R and Chakrabarti S: Glucose-induced cell signaling in the pathogenesis of diabetic cardiomyopathy. Heart Fail Rev 19 75-86, 2014.

25. Rodrigues B, Cam MC and McNeill JH: Metabolic disturbances in diabetic cardiomyopathy. Mol Cell Biochem 180: 53-57, 1998.

26. Cheng Y, Ndisang JF, Tang G, Cao K and Wang R: Hydrogen sulfide-induced relaxation of resistance mesenteric artery beds of rats. Am J Physiol Heart Circ Physiol 287: H2316-H2323, 2004.

27. Ali MY, Ping CY, Mok YY, Ling L, Whiteman M, Bhatia M and Moore PK: Regulation of vascular nitric oxide in vitro and in vivo; a new role for endogenous hydrogen sulphide? Br J Pharmacol 149: 625-634, 2006.

28. Hosoki R, Matsuki $\mathrm{N}$ and Kimura $\mathrm{H}$ : The possible role of hydrogen sulfide as an endogenous smooth muscle relaxant in synergy with nitric oxide. Biochem Biophys Res Commun 237: 527-531, 1997.

29. Kiss L, Deitch EA and Szabo C: Hydrogen sulfide decreases adenosine triphosphate levels in aortic rings and leads to vasorelaxation via metabolic inhibition. Life Sci 83: 589-594, 2008.

30. Lim JJ, Liu YH, Khin ES and Bian JS: Vasoconstrictive effect of hydrogen sulfide involves downregulation of cAMP in vascular smooth muscle cells. Am J Physiol Cell Physiol 295: C1261-C1270, 2008

31. Abe $\mathrm{K}$ and Kimura $\mathrm{H}$ : The possible role of hydrogen sulfide as an endogenous neuromodulator. J Neurosci 16: 1066-1071, 1996.

32. Hu LF, Wong PT, Moore PK and Bian JS: Hydrogen sulfide attenuates lipopolysaccharide-induced inflammation by inhibition of p38 mitogen-activated protein kinase in microglia. J Neurochem 100: 1121-1128, 2007.

33. Li L, Bhatia M and Moore PK: Hydrogen sulphide-a novel mediator of inflammation? Curr Opin Pharmacol 6: 125-129, 2006.

34. Johansen D, Ytrehus K and Baxter GF: Exogenous hydrogen sulfide $(\mathrm{H} 2 \mathrm{~S})$ protects against regional myocardial ischemia-reperfusion injury-Evidence for a role of K ATP channels. Basic Res Cardiol 101: 53-60, 2006.

35. Elrod JW, Calvert JW, Morrison J, Doeller JE, Kraus DW, Tao L, Jiao X, Scalia R, Kiss L, Szabo C, et al: Hydrogen sulfide attenuates myocardial ischemia-reperfusion injury by preservation of mitochondrial function. Proc Natl Acad Sci USA 104: 15560-15565, 2007

36. Jain SK, Bull R, Rains JL, Bass PF, Levine SN, Reddy S, McVie R and Bocchini JA: Low levels of hydrogen sulfide in the blood of diabetes patients and streptozotocin-treated rats causes vascular inflammation? Antioxid Redox Signal 12: 1333-1337, 2010.
37. Yusuf M, Kwong Huat BT, Hsu A, Whiteman M, Bhatia M and Moore PK: Streptozotocin-induced diabetes in the rat is associated with enhanced tissue hydrogen sulfide biosynthesis. Biochem Biophys Res Commun 333: 1146-1152, 2005.

38. Du J, Hui Y, Cheung Y, Bin G, Jiang H, Chen X and Tang C: The possible role of hydrogen sulfide as a smooth muscle cell proliferation inhibitor in rat cultured cells. Heart Vessels 19: 75-80, 2004.

39. Hu LF, Lu M, Wu ZY, Wong PT and Bian JS: Hydrogen sulfide inhibits rotenone-induced apoptosis via preservation of mitochondrial function. Mol Pharmacol 75: 27-34, 2009.

40. Oh GS, Pae HO, Lee BS, Kim BN, Kim JM, Kim HR, Jeon SB, Jeon WK, Chae HJ and Chung HT: Hydrogen sulfide inhibits nitric oxide production and nuclear factor-kappaB via heme oxygenase-1 expression in RAW264.7 macrophages stimulated with lipopolysaccharide. Free Radic Biol Med 41: 106-119, 2006.

41. Tripatara P, Patel NS, Collino M, Gallicchio M, Kieswich J, Castiglia S, Benetti E, Stewart KN, Brown PA, Yaqoob MM, et al: Generation of endogenous hydrogen sulfide by cystathionine gamma-lyase limits renal ischemia/reperfusion injury and dysfunction. Lab Invest 88: 1038-1048, 2008.

42. Tamizhselvi R, Moore PK and Bhatia M: Inhibition of hydrogen sulfide synthesis attenuates chemokine production and protects mice against acute pancreatitis and associated lung injury. Pancreas 36: e24-e31,2008.

43. Sivarajah A, McDonald MC and Thiemermann C: The production of hydrogen sulfide limits myocardial ischemia and reperfusion injury and contributes to the cardioprotective effects of preconditioning with endotoxin, but not ischemia in the rat. Shock 26: 154-161,2006.

44. Boudina S and Abel ED: Diabetic cardiomyopathy, causes and effects. Rev Endocr Metab Disord 11: 31-39, 2010.

45. Zheng X, Zhu S, Chang S, Cao Y, Dong J, Li J, Long R and Zhou Y: Protective effects of chronic resveratrol treatment on vascular inflammatory injury in steptozotocin-induced type 2 diabetic rats: Role of NF-kappaB signaling. Eur J Pharmacol 720: 147-157, 2013.

46. MacMicking J, Xie QW and Nathan C: Nitric oxide and macrophage function. Annu Rev Immunol 15: 323-350, 1997.

47. Bardell AL and MacLeod KM: Evidence for inducible nitric-oxide synthase expression and activity in vascular smooth muscle of streptozotocin-diabetic rats. J Pharmacol Exp Ther 296: 252-259, 2001.

48. Alhouayek M and Muccioli GG: COX-2-derived endocannabinoid metabolites as novel inflammatory mediators. Trends Pharmacol Sci 35: 284-292, 2014.

49. Zamorano B and Carmona MT: Prostaglandin-E2 and cyclic adenosine 3'-5' monophosphate levels in the hypertrophied rat heart. Biol Res 25: 85-89, 1992.

50. Song ZF, Chen DY, DU B and Ji XP: Poly (ADP-ribose) polymerase inhibitor reduces heart ischaemia/reperfusion injury via inflammation and Akt signalling in rats. Chin Med J (Engl) 126: 1913-1917, 2013.

51. Liu ZF, Zheng D, Fan GC, Peng T and Su L: Heat stress prevents lipopolysaccharide-induced apoptosis in pulmonary microvascular endothelial cells by blocking calpain/p38 MAPK signalling. Apoptosis 21: 896-904, 2016.

52. Dong Y, Yin S, Song X, Huo Y, Fan L, Ye M and Hu H: Involvement of ROS-p38-H2AX axis in novel curcumin analogues-induced apoptosis in breast cancer cells. Mol Carcinog 55: 323-334, 2016

53. Han OJ, Joe KH, Kim SW, Lee HS, Kwon NS, Baek KJ and Yun HY: Involvement of p38 mitogen-activated protein kinase and apoptosis signal-regulating kinase-1 in nitric oxide-induced cell death in PC12 cells. Neurochem Res 26: 525-532, 2001. 